\title{
DESARROLLO SINTÁCTICO DE UNA FAMILIA DE CONSTRUCCIONES CON GANA Y FIJACIÓN DE LAS CONSTRUCGIONES DE INDEFINICIÓN CON "DAR LA GANA"
}

\author{
SYNTACTIC DEVELOPMENT OF A FAMILY \\ OF CONSTRUCTIONS WITH GANA AND THE FIXATION \\ OF INDEFINITENESS CONSTRUCTIONS \\ WITH "DAR LA GANA"
}

\author{
Liliana Ruiz Velasco Dávalos \\ rliliana_@hotmail.com
}

RESUMEN: El presente trabajo busca describir el desarrollo diacrónico en el español clásico y moderno de la sintaxis de una familia de construcciones con el verbo dary el sustantivo gana. Para ello se recurrió al CORDE y se analizaron los patrones de uso de estas construcciones en sus rasgos semánticos y sintácticos básicos (roles, sujeto y complementos), además de su diferenciación semántica, y de las construcciones en que se insertan. Los resultados indican que se da una diferenciación de las distintas construcciones y sus patrones de uso, de manera que una de ellas, DAR la gana, se caracteriza por participar en construcciones indefinidas.

Palabras clave: español clásico; español moderno; indefinición; construcciones; cambio lingüístico.

Abstract: The present study deals with the diachronic development in Classical and Modern Spanish of a familiy of syntactical constructions composed of the verb darand the noun gana. For that matter data were collected from CORDE and a study was made of their basic semantic and syntactic features (roles, subject and complements), of their semantic differentiation, as well as of the constructions of which they formed part. The results point to a syntactic differentiation between the constructions and their use patterns, leading to one of them, DAR la gana, being selected by speakers to form indefinite constructions.

Keywords: Classical Spanish; Modern Spanish; indefiniteness; constructions; language change.

Recepción: 10 de mayo de 2017; aceptación: 8 de marzo de 2019. 
El presente trabajo estudia la diacronía de una familia de construcciones con gana. Observemos los siguientes ejemplos, provenientes de textos literarios del siglo xx:

(1) Haz lo que quieras, puedes hacer lo que te dé gana (s. $\mathrm{xx}$, Camilo José Cela, La colmena) ${ }^{1}$.

(2) Hasta a mí me da gana de dale un rial a esa pobre gente (s. xx, Tomás Carrasquilla, Hace tiempos).

En (2) nos inclinaríamos por interpretar el enunciado como "Hasta a mí me dan ganas de darle...", mientras que en (1) nos decantaríamos más por "Puedes hacer lo que te dé la gana". La diferencia entre ambos se debe a que el español ha desarrollado dos construcciones: DAR la gana y DAR ganas. Cada una permite señalar distintos matices de la modalidad de enunciación orientada al agente (sobre este concepto, cf. Bybee et al. 1994, pp. 176 ss.). La primera, DAR la gana, indica una disposición mental del individuo, que podría identificarse con la "voluntad" y por la que se dan las condiciones internas en el individuo para actuar; la segunda, DAR ganas, indica una disposición más general del individuo, que abarca desde la sensación física hasta el "deseo" y por la que se dan ciertas condiciones internas o externas, esto es, condiciones físicas, mentales o sociales para actuar. Así, "le dieron ganas de ir al baño" puede entenderse como una sensación física o como un deseo, sin que implique su realización; en cambio, "(se) le dio la gana ir al baño" se entiende como una acción que efectivamente se llevó a cabo movida por la voluntad. Asimismo, como suele ocurrir en los procesos de cambio lingüístico, cada una de estas construcciones ha adquirido determinados rasgos, se ha especializado y aparece más en cierta configuración sintáctica que en otra. En contraste, la forma en singular y sin artículo, como en los ejemplos, permanece ambigua.

La pregunta es cómo se han ido fijando estas construcciones. Para ello nos centramos en el desarrollo de las configuraciones sintácticas en que aparecen, concretamente en el llamado español medio, o clásico, y el moderno (cf. Eberenz 2009; Lapesa 1981; Melis et al. 2003). Con base en estas configuraciones sintácticas veremos que DAR la gana se distingue por participar

${ }^{1}$ Todos los ejemplos, salvo que se indique lo contrario, provienen del Corpus diacrónico del español (CORDE), de la Real Academia Española. 
en las fórmulas de indefinición y en la construcción más particular: HACER + lo que + \{DARLE la gana $/ . .$.$\} , como aparece en (1).$

En lo que sigue, se presenta brevemente un marco teóricometodológico y una caracterización general de las construcciones que aquí nos ocupan. Enseguida pasamos al análisis diacrónico más detallado comparando las distintas construcciones con gana, para lo que se incluyen tres procesos: el establecimiento de sus rasgos semántico-sintácticos básicos (roles, relaciones de sujeto y complementos), su diferenciación semántica y la especialización de DAR la gana en las construcciones de indefinición. Cerramos con algunas consideraciones finales.

\section{ANÁlisis CONSTRUCGIONAL Y DIACRONÍA}

El tratamiento de estas construcciones en la bibliografía lingüística ha sido más bien tangencial. Se mencionan al tratar la construcción darle \{miedo/ pena/ coraje/...\} (Fernández Ramírez 1986, p. 128; Fernández Soriano y Táboas Baylín 1999, § 27.3.6) o no se mencionan (p.ej., Alcina y Blecua 1975; Delbecque y Lamiroy 1999; Seco 1978), dejando su tratamiento a los tratados de fraseología (p.ej. Corpas Pastor 1996, p. 127) o los diccionarios, que incluyen o no una serie de colocaciones para el sustantivo en cuestión, esto es, gana (p.ej., Seco et al. 1999). Así, estas construcciones normalmente se dejan fuera de lo que se considera el núcleo gramatical, sea por considerarlas parte de la parole o la actuación lingüística y porque su tratamiento corresponde al terreno del léxico, o de manera más amplia, por el bias escritural (apud Linell 2005), por el que dentro de la gramática se incluyen construcciones de cierta tradición y se dejan fuera aquellas que se considera son propias de la oralidad o llevan una marca diafásica de informal. Consecuencia de ello, en parte, es que en la bibliografía consultada no encontramos una diferenciación clara entre las distintas construcciones de DAR gana, DAR la gana y DAR ganas.

La llamada gramática construccional, inscrita en el paradigma funcionalista asumido en este trabajo, ofrece una alternativa para su tratamiento al considerar que en la descripción gramatical entran tanto aquellas construcciones consideradas nucleares como aquellas consideradas más periféricas, pues no se hace una distinción tajante entre léxico y gramática (Fillmore et al. 1988). En este marco, las construcciones son considera- 
das signos de variable extensión, esto es, agrupaciones de forma y significado. Pueden estar completamente fijadas lexicalmente o tener un carácter esquemático, polos entre los que se da un continuo (Fillmore et al. 1988; Goldberg 1995). En la gramática, entendida como el saber idiomático (en la terminología de Coseriu), las construcciones están ligadas entre sí, con lo que forman un conjunto estructurado por el que mantienen diversos vínculos. Goldberg (1995, pp. 72-81) señala que las construcciones se relacionan entre sí cuando una construcción hereda ciertas propiedades de otra y los vínculos que las unen pueden ser de distintos tipos: de polisemia, cuando se dan varios sentidos relacionados entre sí con uno más central que los otros; de subparte, cuando una construcción conserva parte de los rasgos de otra; de instancia, cuando una construcción es un caso especial de otra; de extensión metafórica, cuando una de ellas es una metáfora de otra. A estos vínculos podrían añadirse otros tipos de asociación identificados en el terreno del léxico, como las relaciones cotaxonómicas o de contigüidad (cf. Blank 2001, pp. 43-44).

Desde el punto de vista diacrónico, se ha señalado que los procesos de cambio lingüístico inician con una innovación en el discurso, la cual adquiere difusión al ser retomada por otros individuos hasta generalizarse, emplearse en otros contextos y convencionalizarse (cf., p.ej., Blank 2001, pp. 69 ss.). Los procedimientos empleados por los hablantes para comunicarse, y que llevan al cambio lingüístico, incluyen la metáfora, la metonimia, generalización, absorción del contexto, etc. (Blank 2001, pp. 74-95; Bybee et al. 1994, pp. 282-297; Hopper \& Traugott 2003). En un primer momento, esta creatividad individual desempeña una función importante, si bien el cambio propiamente lingüístico ocurre cuando se convierte en parte de la norma de una comunidad, lo que puede llevar a un cambio tipológico (cf. Coseriu 1988). Como resultado, en cualquier corte sincrónico que se haga de la lengua se advierte gradualidad y variación en las categorías, se retienen rasgos y funciones diversos, unos más antiguos que otros, y se encuentran diferentes construcciones que compiten entre sí, de manera que en un estadio de lengua en particular se observan las distintas capas que se han ido superponiendo (Bybee et al. 1994, pp. 15-22; Bybee 2010, pp. 2-7; Coseriu 1988; Hopper \& Traugott 2003, pp. 124-126).

Suelen distinguirse dos macroprocesos de cambio lingüístico: la lexicalización y gramaticalización; la primera designa 
el macroproceso por el que las unidades lingüísticas pasan a formar parte del léxico (Lehmann 1989 y 2002a), mientras que la segunda remite al macroproceso por el que un elemento adscrito al léxico de una lengua se vuelve gramatical, o bien, por el que un elemento gramatical se hace más gramatical (Lehmann 1985; Hopper \& Traugott 2003, p. 1; Bybee et al. 1994, p. 4). Según Lehmann (1985 y 2002, pp. 112-143), la gramaticalización involucra varios subprocesos: atrición, relacionado con la pérdida de rasgos fónicos y semánticos; paradigmatización, es decir, la adscripción a un paradigma reducido y cerrado; obligatorización, en que la elección de la unidad lingüística en cuestión se vuelve obligatoria; condensación, si el elemento pasa a modificar una palabra o raíz; coalescencia, relativo a si pasa de estar yuxtapuesto a funcionar como afijo; fijación, relacionada con una menor variabilidad sintagmática. Según qué tanto se hayan puesto en marcha tales procesos encontraremos un continuo de elementos más o menos léxicos, más o menos gramaticales. Desde la perspectiva asumida en este trabajo, la gramaticalización va asociada a una mayor esquematicidad de las construcciones, con significados más abstractos, y la lexicalización, a una menor esquematicidad, que da mayor peso a significados más concretos.

Tomando en cuenta lo anterior, podemos ofrecer una primera descripción general de las construcciones en cuestión antes de pasar a su desarrollo diacrónico.

\section{Caracterización de DAR GANA Y CONEXAS}

Por lo que se observa en el nivel sincrónico del español actual, en las construcciones que nos ocupan cobran relevancia cuatro de los procesos señalados por Lehmann: paradigmatización, condensación, fijación y atrición.

En lo tocante a la paradigmatización, se observa que más que participar en un paradigma fuertemente gramaticalizado, se ha dado una reducción para expresar la modalidad mediante la alternancia de estas construcciones frasales con unidades como los auxiliares verbales (p.ej., querer). Esta paradigmatización tiene mayor peso gramatical en las fórmulas de indefinición en las que se requiere de una expresión verbal de disposición mental; la construcción seleccionada como parte de ese paradigma es DAR la gana (cf. "Fórmulas indefinidas"). Asimismo, como 
paso previo al establecimiento de estas construcciones, de los posibles complementos del verbo dar ha habido una primera reducción a los sustantivos de emoción, de manera que gana se integra inicialmente en ese paradigma para formar las construcciones sintácticas que nos interesa examinar aquí (cf. "Rasgos sintácticos generales”).

Respecto a la condensación, cabe considerar un continuo que va de la expresión de la modalidad discursivamente, mediante diversos signos desperdigados a lo largo de un enunciado de variada extensión, a la expresión que se da en el modo gramatical (p.ej., el subjuntivo) mediante un afijo. Como categorías intermedias entrarían los auxiliares y las locuciones. Con DAR la gana, DAR ganas, la expresión de la modalidad se habría condensado en una locución. En un sentido más relevante, en estas construcciones, como veremos, hay una fuerte tendencia a reducir sus posibilidades combinatorias para limitarse a aceptar complementos de tipo oracional (cf. "La oración completiva"). Con las fórmulas de indefinición, más gramaticalizadas, las posibilidades combinatorias se reducen a un nexo (que, como, cuanto, etc.) (cf. "Nexo").

En lo que hace a la fijación, en el nivel sincrónico se advierte que se trata de expresiones relativamente fijas en cuanto muestran diversas restricciones sintácticas (cf. Ruiz Velasco 2017). Sin embargo, los elementos que las componen no han perdido su estatus categorial, por lo que resulta aceptable cierto margen de variabilidad. Así, con DAR la gana, gana ha perdido libertad combinatoria hoy en día, pero todavía se analiza como sustantivo, con marcas de género y número, por lo que la construcción permite la presencia de adjetivos intensificadores, como pueden ser real/ regalada/ puta/ chingada/ santísima (mas no modificadores); y puesto que la frase todavía se analiza como una oración, es posible emplear se (id.) y que el verbo reciba marcas flexionales de tiempo, aspecto y modo.

Finalmente, respecto a la atrición, o más precisamente, desemantización, en el español actual la construcción DAR la gana se emplea en ocasiones como mera marca de indefinición, con lo que pierde el significado modal volitivo proveniente de gana con el significado de 'voluntad'. Ello se hace evidente en usos como el siguiente, con una fórmula de indefinición:

(3) Es que si es el caso que ha sido porque a mi me ha dado la gana, porque yo he tenido un descuido, pues has tenido un des- 
cuido, te jodes y apechugas (s. xx, CREA, oral, grupo G13, Filología).

Otros rasgos considerados típicos de la gramaticalización, como la erosión fónica o la obligatorización, están ausentes. En ellos no se observa la morfologización de las unidades lingüísticas, típica de la gramaticalización fuerte (cf. Lehmann 2002, p. 12), sino su construccionalización ${ }^{2}$, que se establece en ciertos patrones sintáctico-semánticos constructivos, proceso al que dedicaremos mayor atención en el apartado siguiente.

Las construcciones que aquí nos ocupan, si se considera la forma prototípica de cada una de ellas, han ido formando una familia, como puede apreciarse en el Esquema 1.

El esquema muestra tanto las relaciones sincrónicas que se dan en el español contemporáneo como diacrónicas entre las construcciones. Esto es, de la construcción con el verbo dar con un sustantivo de afección surge la forma DAR gana, a partir de la cual surgirían más adelante las construcciones DAR la gana y DAR ganas. A su vez, la construcción DAR la gana ha dado origen en el español contemporáneo a las construcciones PEGÁRSELE la gana e HINCHÁRSELE la gana (Ruiz Velasco 2017). Es decir, antes que producirse una mayor fijación y gramaticalización, en el español (mexicano) esta construcción se ha renovado mediante el empleo de otros elementos léxicos (pegar, hinchar), con los que se busca mayor expresividad ${ }^{3}$. De modo semejante, la construcción DAR ganas se renovó con la forma ENTRARLE ganas, en la que también se emplea otro elemento verbal ${ }^{4}$.

${ }^{2}$ FRIED (2013, p. 424) define construccionalización como "a process that leads to (1) the emergence of a new grammatical pattern (construction) out of previously independent material or (2) a reorganization of an existing construction, leading to an increasingly more opaque meaning of the pattern”.

${ }^{3}$ Una búsqueda en los textos orales del Corpus de referencia del español actual (CREA), de la Real Academia Española, no arroja ningún resultado para la variante con hincharse, mientras que para la variante con pegar todos los casos corresponden al español mexicano.

${ }^{4}$ Según una búsqueda rápida en el CORDE, esta construcción se documenta a partir del último tercio del s. Xix. En el esquema no se incluye la forma VENIRLE en gana, de semántica similar a DAR la gana, mas con un patrón distinto al incluir la preposición en. 


\section{ESQUEMA 1}

Familia de construcciones de DAR gana ${ }^{5}$

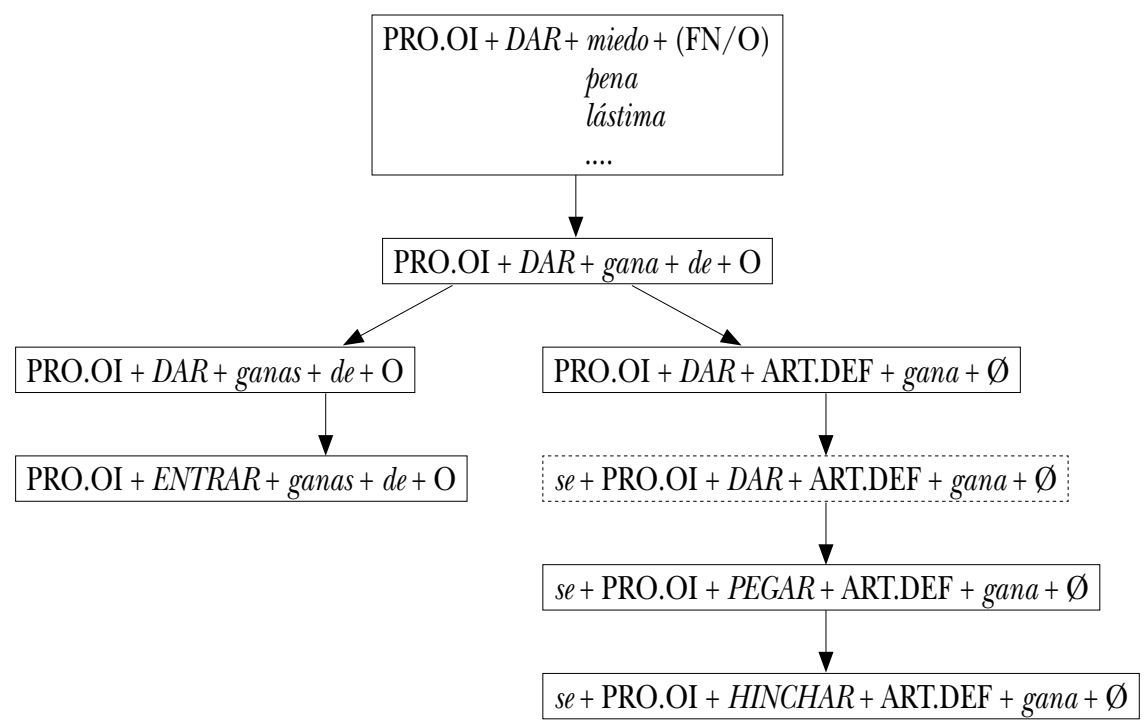

Fuente: Ruiz Velasco 2017, con algunas modificaciones.

Común a estas construcciones es la presencia de dos argumentos: uno con el rol semántico de 'recipiente' o, mejor dicho, experimentante, el cual se expresa mediante un pronombre de objeto indirecto, y otro con el rol de 'contenido', que se ha establecido como una oración completiva -de infinitivo o con un verbo finito- que puede omitirse por razones pragmáticas. Se trata, pues, de construcciones con un núcleo sustantivo en las que están previstos huecos esquemáticos, por lo que se sitúan en un punto intermedio en el continuo entre aquellas construcciones completamente fijadas lexicalmente y aquellas completamente esquemáticas (Ruiz Velasco 2017).

Las construcciones con verbos como dar suelen caracterizarse como construcciones con verbos de soporte, los cuales prototípicamente son verbos frecuentes, vacíos semánticamente, que van acompañados por una frase nominal para formar

${ }^{5}$ Las flechas indican vínculos entre las construcciones; cada caja señala una construcción, mientras que la caja con línea punteada indica que se trataría de una instancia particular o variante (pero cf. infra "La oración completiva"). 
locuciones, cargando con las marcas de persona y número, así como con las de tiempo, aspecto y modo, y que suelen conllevar un matiz aspectual de la acción (Gross et Vivès 1986, pp. 14, 18-20). Desde una perspectiva transformacional, las construcciones con verbos de soporte presentan tres propiedades: inalienabilidad, doble análisis y reducibilidad a una nominalización (Giry-Schneider 1986, pp. 51-52; Gross et Vivès 1986, pp. 13-15). Así, respecto a la determinación del sustantivo, ninguna de las construcciones con gana admite un complemento de+ Nhum o un posesivo, a menos que sea correferencial con el objeto indirecto (p.ej., "Haz lo que te dé tu gana"). En cuanto a la segunda propiedad, presentan restricciones para un doble análisis. Con DAR ganas se permite la extracción del complemento: "Es de salirme de lo que me dan ganas"; resulta en cambio más dudosa la extracción "Es ganas de salirme lo que me dan", al separar verbo y sustantivo, lo que muestra su grado de cohesión; mientras que con DAR la gana no es posible ninguna de las dos (“*Es de salirme de lo que me da la gana"; "*Es la gana de salirme lo que me da") ${ }^{6}$. Finalmente, el plural ganas permite su empleo en una frase nominal sin el apoyo del verbo ("Las ganas de Pedro de abrazarla”), no así la forma singular ("*La gana de Pedro de abrazarla"). Ello nos habla de la idiomaticidad del sustantivo gana que presenta restricciones combinatorias. En su carácter de construcciones periféricas, ninguna de las dos se ajusta del todo a la caracterización prototípica de una construcción con un verbo de soporte aun cuando conserven otros rasgos, como su carácter aspectual, en este caso, incoativo.

En lo que sigue, nos ocupamos de las construcciones que aparecen en la parte media del esquema (DAR gana, DAR la gana, DAR ganas) y vemos cómo se han constituido diacrónicamente, además de las configuraciones sintácticas en que participan. En cuanto a los datos empleados para este trabajo, hemos recurrido al Corpus diacrónico del español (CORDE), de la Real Academia Española y reunido todos los casos que arrojaba para este tipo de construcciones con gana, del siglo Xvi, en que surge la primera, al siglo XIX ${ }^{7}$. Este enfoque nos brinda la ventaja de obtener un mayor número de casos para el análisis.

${ }^{6}$ Otro tipo de prueba, como su pasivización, es bloqueada por ambas construcciones: "*las ganas de salir le fueron dadas"; "*las ganas le fueron dadas de salir"; "*la gana de salir le fue dada; "*la gana le fue dada de salir".

7 Puesto que el corpus no está etiquetado para la consulta esquemática, se hicieron búsquedas específicas de "DAR gana” y las otras colocaciones en 


\section{ANÁLISIS DIACRÓNICO}

\section{Primeras documentaciones}

El sustantivo gana es de origen incierto; algunos lo consideran un préstamo germánico de la época en que los visigodos reinaban en España y se fijó en una serie de construcciones de carácter adverbial (p.ej., de buena gana, con gana) y verbal (p.ej., avía gana, prísole ganas) (Penny 2014, p. 292; Cuervo 1998; también Corominas 1955). La colocación DAR gana se documenta por primera vez, según los datos del CORDE, en el siglo XVI, alrededor de 1540-1553 (cf. 4a). A partir de ella, surgirían DAR la gana (4c) y DAR ganas $(4 d)$-los primeros ejemplos documentados se dan en 1654-1658 y 1768, respectivamente-así como una forma no concordada con ganas ( $4 b$ ) en la que el verbo se conjuga en singular, DAR.SG. ganas, la cual se documenta ya en 1620:

(4) a. CAÇA, quita los malos pensamientos e la saña, e da gana de comer al que lo acostumbra, e de dormir (s. XVI, Hugo de Celso, Repertorio universal de todas las leyes de estos reinos de Castilla).

$b$. El çumo de Tabaco en cantidad de media onza, con una quarta de Theriaca, i tres onzas de cocimiento de Hinoxo, deshaze qualquiera opilación, mata las lombrizes, quita el ahíto, da ganas de comer, consume las flegmas... (s. XVII, Juan de Castro, Historia de las virtudes y propiedades del tabaco...).

c. ...y come en su coche donde le halla y le da la gana, ya de figón, ya de pastelería... (s. XVII, Jerónimo de Barrionuevo, Avisos).

d. En acordándome de esto me dan ganas de molerla... (s. xviII, Ramón de la Cruz, El mesón de Villaverde).

La distribución por siglo de cada uno de estos patrones en el corpus se da como sigue:

cada uno de los tiempos verbales simples, y para cada uno de los siglos. Este tipo de búsqueda es más eficiente con el corpus susodicho, pero tiene sus limitantes, ya que no permite ver si en algunos casos se da algún elemento interpuesto o la anteposición del sustantivo. Algunos datos numéricos aquí reportados difieren ligeramente de los presentados en Ruiz Velasco 2017 al incluirse unos cuantos casos más en que se daba una variante ortográfica; sin embargo, no se modifican las tendencias generales en los rasgos ahí considerados. 
Cuadro 1

Frecuencia absoluta de DAR gana y conexas por siglo (ss. XVI-XIX) ${ }^{8}$

\begin{tabular}{lccccc}
\hline & s. XVI & s. XVII & s. XVIII & s. XIX & TOTAL \\
\hline DAR gana & 24 & 34 & 30 & 43 & 131 \\
DAR la gana & & 2 & 47 & 356 & 405 \\
DAR.SG. ganas & & 2 & 2 & 12 & 16 \\
DAR ganas & & & 4 & 88 & 92 \\
TOTAL & 24 & 38 & 83 & 499 & 644 \\
\hline
\end{tabular}

Así pues, DAR gana habría surgido en el siglo Xvi o al menos en el xv, como señala Fernández Ramírez para las construcciones de dar con un sustantivo de afección (1986, § 19, nota 51). A partir del Cuadro 1 se puede observar que la colocación DAR gana sólo experimenta un ligero aumento y se mantiene estable en el rango de 20 a 50 casos por siglo. En cambio, la colocación DAR.SG. ganas tuvo poca difusión y se mantuvo con una escasa productividad hasta el siglo XIX (12 casos). En contraste, para las otras dos colocaciones, su uso aumenta considerablemente en el s. XIX, particularmente en el caso de DAR la gana (356 casos). Tal aumento se relaciona con su fijación en las fórmulas de indefinición, para las que se selecciona DAR la gana, se trate de una fórmula que modifica al predicado, con el esquema NEXo SUbORDINANTE + EXPRESIÓN VERBAL DE DISPOSICIÓN MENTAL o de una fórmula para expresar la indefinición de la acción, típicamente con el esquema HACER + lo que + EXPRESIÓN VERBAL DE DISPOSICIÓN MENTAL (cf. infra "Fórmulas indefinidas").

Veamos, pues, cómo se desarrollan tales patrones para formar construcciones.

\section{RASGOS SINTÁCTICOS GENERALES}

Según hemos dicho, al trabajar con los siglos del xvi al xix, el presente estudio abarca las etapas correspondientes a lo que se ha llamado español medio, o clásico, y parte del español moder-

8 Éste y todos los cuadros que siguen son elaboración propia a partir de los casos que arroja el CORDE. 
no. Diversos estudios han señalado que la época de los Siglos de Oro, correspondiente al español medio, es un período lleno de cambios en que se observa una fuerte reacomodación del sistema lingüístico. La etapa concerniente al español moderno se caracterizaría por una fijación de normas más próximas al español actual y, según el autor, habría iniciado a partir del siglo XVIII o el XIX (Eberenz 2009; Lapesa 1981; Melis et al. 2003). Por lo que toca a las construcciones aquí tratadas, es en el período que abarca los siglos XVIII y xix que tienden a establecerse ciertos rasgos. En lo que sigue examinamos tres de ellos: el sujeto, el objeto indirecto y el complemento de tipo oracional. La colocación con mayor variabilidad, que no llega a fijarse, precisamente por su escasa difusión y productividad, es DAR.SG. ganas.

\section{El sujeto}

Para el siglo XVI, las primeras documentaciones con DAR gana forman parte del proceso de extensión metafórica de la construcción de transferencia con el verbo dar. Del significado concreto, la transferencia de un objeto, se empezó a señalar la transferencia abstracta de una emoción: DAR $\{\text { miedo/ pena } / . . .\}^{9}$. El esquema constructivo original de transferencia incluye tres participantes: un agente (sujeto), un tema-paciente (objeto directo) y un recipiente (objeto indirecto). Parte de ese esquema constructivo es heredado por DAR \{miedo/ pena...\}: el tema-paciente equivale al sustantivo de afección en cuestión; al recipiente, si bien conserva cierto matiz como tal, se superpone el rol de experimentante al "recibir" una emoción o cualidad mental, y el agente pasa a ser un participante con el rol de causa. Este esquema de transferencia abstracta es trasladado a DAR ganay se hace presente cuando se enuncia un sujeto con el rol semántico de causa:

(5) y cuido que mi pracer le da gana de comer (s. XVI, Juan de Timoneda, La oveja perdida).

La construcción obedece pues al siguiente esquema sintáctico-semántico:

${ }^{9}$ El papel de este tipo de metáfora, del dominio de lo concreto a lo abstracto, se ha señalado con frecuencia en el cambio lingüístico. Cf. BybeE et al. 1994, p. 283; Hopper \& Traugott 2003, pp. 84-85; LAKoff y Johnson 1986. 


\begin{tabular}{|cccc|}
\hline SUJ & OI & OD \\
causa & experimentante & tema \\
mi pracer & $l e$ & $d a$ & gana de comer \\
\hline
\end{tabular}

Este esquema con un sujeto-causa lo encontramos nuevamente con DAR.SG. ganas y con DAR ganas:

(6) a. El emplasto de las uvillas de este árbol majadas aplicado caliente sobre el estómago flaco, lo conforta, da ganas de comer y repara los vómitos (s. XviI, Bernabé Cobo, Historia del Nuevo Mundo).

$b$. porque aquellos hombres, tan hombres, tan bien equipados, limpios como el oro, con sus petos encarnados y sus tricornios galoneados de blanco sobre aquellos hermosos caballos, trotando al son de esos clarines que dan escalofríos al que tiene metido en el alma el sentimiento de la patria, daban ganas de gritar: ¡Viva la guardia civil! (s. XIX, Eusebio Blasco, Páginas intimas).

En (6a) el emplasto de las uvillas... funge como sujeto-causa de da ganas de comer; en (6b) es aquellos hombres... la frase que actúa como sujeto de daban ganas de gritar. El Cuadro 2 muestra la distribución diacrónica de este esquema por colocación:

\section{CUADro 2}

Distribución del esquema con un sujeto-causa por colocación (en porcentaje) $(\text { ss. XVI-XIX) })^{10}$

\begin{tabular}{|c|c|c|c|c|c|c|c|c|}
\hline \multirow[b]{2}{*}{ DAR gana } & \multicolumn{2}{|c|}{ s. XVI } & \multicolumn{2}{|c|}{ s. XVII } & \multicolumn{2}{|c|}{ s. XVIII } & \multicolumn{2}{|c|}{ s. XIX } \\
\hline & $29 \%$ & $(7 / 24)$ & $8.8 \%$ & $(3 / 34)$ & $6.6 \%$ & $(2 / 30)$ & $2.3 \%$ & $(1 / 43)$ \\
\hline DAR la gana & & & $0 \%$ & $(0 / 2)$ & $0 \%$ & $(0 / 47)$ & $0 \%$ & $(0 / 356)$ \\
\hline DAR.SG. ganas & & & $100 \%$ & $(2 / 2)$ & $0 \%$ & $(0 / 2)$ & $33 \%$ & $(4 / 12)$ \\
\hline DAR ganas & & & & & $0 \%$ & $(0 / 4)$ & $4.5 \%$ & $(4 / 88)$ \\
\hline
\end{tabular}

${ }^{10}$ Se excluyen los casos ambiguos, pero se incluyen aquellos que se dan en una oración de relativo, p.ej.: "...pues se hace de las dos un pataborrillo que causa asco al estómago francés y da gana de vomitar al castellano" (s. XVIII, José Francisco de Isla, Historia del famoso predicador Fray Gerundio de Campazas alias Zotes). 
Como puede apreciarse, con DAR gana va disminuyendo este esquema constructivo: $29 \%>8.8 \%>6.6 \%>2.3 \%$, mientras que con DAR.SG. ganas resulta particularmente notorio, pues en el siglo XIX equivale al 33\% (4 de 12 casos) y con DAR ganas se da escasamente $(4.5 \%)$. Finalmente, con DAR la gana no aparece ningún caso con un sujeto-causa en los períodos considerados.

El esquema, decíamos, comunica una transferencia abstracta. Ahora bien, ya en el siglo XVI, es decir, desde las primeras documentaciones de DAR gana, dicho esquema convive con otro en el que no se enuncia un sujeto-causa:

(7) ¿qué es la razón que si un hombre tiene deseo del acto carnal, ha vergüenza de manifestarlo, y si le da gana de comer, o beber, o de cualquier cosa de este género, no tiene empacho de manifestarlo? (s. Xvi, Juan Huarte de San Juan, Examen de ingenios para las ciencias).

Con él, semánticamente se pierde el significado de transferencia y se comunica uno de tipo incoativo. Sintácticamente, se trata de una estructura ambigua, pues al no presentar un sujeto-causa no es transparente qué determina la flexión en singular del verbo. El empleo de DAR.SG. ganas sin un sujeto-causa, como se documenta desde el siglo XviII, evidencia que algunos hablantes han interpretado la construcción como impersonal:

(8) Deseara también saber a qué hora acostumbráis iros a acostar, pues no sé si podremos volver antes que anochezca. Volved cuando os dé ganas o cuando podáis, pues la hora en que llegarais esa será para mí la de disponer la cena... (s. XVIII, Pedro Montengón, Eusebio).

El esquema sintáctico-semántico, sin sujeto, es el siguiente:

\begin{tabular}{|ccc|}
\hline OI & & OD \\
experimentante & & tema \\
os & dé & ganas \\
\hline
\end{tabular}

Una segunda solución aparece con el surgimiento de la forma DAR ganas (documentada en el siglo XVIII), con el verbo concordado en plural, y en la que los hablantes han analizado el sujeto sintáctico como el tema ganas (9) y no ya como una causa: 
(9) Cuando leo estas proposiciones de Oráculo en los libros de nuestros vecinos, me dan ganas vehementisimas de revolver sobre ellos (s. XVIII, Juan Pablo Forner, Discursos filosóficos sobre el hombre).

He aquí pues otro esquema constructivo:

\begin{tabular}{|c|c|c|}
\hline$\stackrel{\text { OI }}{\text { experimentante }}$ & & $\begin{array}{l}\text { sUJ } \\
\text { tema }\end{array}$ \\
\hline me & dan & ganas de revolver... \\
\hline
\end{tabular}

En la competencia que se da entre las construcciones DAR. SG. ganas y DAR ganas, concordada, es esta última la que termina por imponerse en el siglo XIX (si descontamos las instancias con un sujeto-causa: 8 vs. 84 casos).

Por lo demás, con DAR la gana se mantendría este tipo de ambigüedad estructural en cuanto a si es impersonal, si el sujeto es el tema (la gana) u otro argumento (el complemento oracional $)^{11}$. Se ha señalado que construcciones de este tipo, con un experimentante topical, presentan cierto conflicto en la distribución de funciones sintácticas (Givón 2001, pp. 194, 205). El empleo de se con esta construcción, como se observa en México y otras regiones, habría sido una solución -en algunas variedades al menos- para transparentar la estructura de la construcción, al interpretar los enunciados y marcarlos explícitamente como oraciones de voz media. Qué tanto cumple una función de este tipo dependerá de qué tanto se dé una alternancia entre las construcciones con y sin $s e$, en cuyo caso no habría que descartar el que se "indique un matiz de «contrario a las expectativas»" (cf. Ruiz Velasco 2017) ${ }^{12}$.

11 En la bibliografía se da cierta discusión respecto al estatus de la completiva en este tipo de construcciones y los autores defienden alternativamente cada una de estas opciones: considerarlas impersonales, con el $\mathrm{SN}$ de tema como sujeto o con la oración completiva -no introducida por preposición en algunas de estas construcciones en el español actual- como sujeto (cf. CANo 1981, pp. 126-127; Fernández Ramírez 1986, p. 128, n. 52; Fernández Soriano y Táboas Baylin 1999, § 27.3.6; Hernanz 1999, $\S 36.3 .2 .4)$.

12 En el corpus aquí trabajado sólo aparecen unos pocos casos (todos con DAR la gana); el primero en el siglo XviII: “¿Adónde se consintiera / que nosotras madruguemos / tanto y que los hombres duerman / hasta que se les dé la gana?" (Ramón de la Cruz, El poeta aburrido). 
El objeto indirecto

El esquema de transferencia al que nos hemos referido incluye un recipiente, que sintácticamente cumple la función de objeto indirecto. Éste puede expresarse mediante una frase preposicional (10); un clítico pronominal, de objeto indirecto, la norma (11a), o de objeto directo, en los pocos casos de laísmo o loísmo que encontramos $(11 b)$; u omitirse, lo cual da como resultado que el experimentante se interprete como genérico (12):

(10) y el agua que corriendo se despeña da gana de beber al que la mira (s. XviI, Juan Méndez Nieto, Discursos medicinales).

(11) a. Diga usted lo que le dé la gana (s. XIx, Leandro Fernández de Moratín, El si de las niñas).

b. y por eso, con lo que decía a Inés no la daba ganas de bostezar (s. XIx, José María de Pereda, La puchera).

(12) Son unos personajes que dan ganas de tirar al blanco (s. XIX, Leopoldo Alas Clarín, Pipá).

Ahora bien, dependiendo de la construcción, se observa un comportamiento distinto respecto a la expresión del recipiente-experimentante mediante un clítico (cf. Cuadro 3).

\section{Cuadro 3}

Presencia del clítico de objeto por colocación (en porcentaje) (ss. XVI-XIX) $)^{13}$

\begin{tabular}{|c|c|c|c|c|c|c|c|c|}
\hline & \multicolumn{2}{|r|}{ s. XVI } & \multicolumn{2}{|c|}{ s. XVII } & \multicolumn{2}{|c|}{ s. XVIII } & \multicolumn{2}{|c|}{ s. XIX } \\
\hline DAR gana & $79 \%$ & $(19 / 24)$ & $76 \%$ & $(26 / 34)$ & $93 \%$ & $(28 / 30)$ & $93 \%$ & $(40 / 43)$ \\
\hline $\mathrm{DAR}$ la gana & & & $100 \%$ & $(2 / 2)$ & $98 \%$ & $(44 / 47)$ & $100 \%$ & $(356 / 356)$ \\
\hline DAR.SG ganas & & & 0 & $(0 / 2)$ & $100 \%$ & $(2 / 2)$ & $58 \%$ & $(7 / 12)$ \\
\hline DAR ganas & & & & & $100 \%$ & $(4 / 4)$ & $76 \%$ & $(67 / 88)$ \\
\hline
\end{tabular}

DAR la gana es la construcción que más requiere el clítico, de manera que para el siglo xIX se fija su presencia, como ocurre con todos los casos encontrados (356), que llevaban alguno

13 Subsumimos aquí cualquier clítico empleado para designar al recipiente-experimentante, incluidos los casos de loísmo y laísmo. 
incorporado. Por su parte, con DAR gana, la construcción más añeja, se advierte un desplazamiento hacia una mayor preferencia por el empleo del clítico en la construcción: del 79-76\% en los siglos XVI y XVII al $93 \%$ en los siglos XVIII y XIX. Con DAR. SG. ganas y DAR ganas se da una marcada variabilidad con los pocos casos que se documentan en los primeros siglos. Para el siglo XIX se observa que toleran más la ausencia del clítico que las otras dos construcciones: con DAR ganas lo encontramos en el $76 \%$ de los casos, y con DAR.SG. ganas, el porcentaje es todavía menor y asciende al 58\%, a pesar de encontrarla documentada con anterioridad. En ella se aprecia la poca fijación que alcanza, pues los enunciados con o sin clítico prácticamente se distribuyen en partes iguales. Se mantiene, por tanto, como una forma sin un patrón constructivo.

Las construcciones que aquí sometemos a examen se comportan de modo peculiar en lo atinente a este rasgo sintáctico. Si bien diacrónicamente la tendencia ha sido que el OI se realice como clítico (Company 2006, pp. 492-493), los porcentajes alcanzados con estas construcciones son muy altos para lo que cabe considerar como la tendencia histórica. Según los datos reportados por Company (2006, cuadro 1, p. 494), en el siglo xiII se realiza como clítico en el $67 \%$ de los casos vs. el $33 \%$ sin clítico; en el s. xvi es el $64 \%$ con clítico vs. el $36 \%$, y en el s. xix es el $60 \%$ vs. el $40 \%$. Con DAR gana no disminuye la presencia del clítico, sino que va en aumento para llegar a un 93\%, y con DAR la gana los porcentajes se mantienen entre 98 y 100\%; en ambos casos, como decíamos, se trata de porcentajes muy altos en comparación con las cifras de Company. Algo menos marcada es la diferencia en el caso de DAR ganas (76\% en el s. XIX), si bien es todavía alto. La colocación que más se acerca a los datos de Company es DAR.SG. ganas, que, sin embargo, oscila bastante sin revelar una tendencia clara, como hemos apuntado. Lo que tenemos pues es un comportamiento diferenciado que depende de los usos para los que cada una va siendo seleccionada.

\section{La oración completiva}

En estas construcciones el sustantivo gana requiere mayor especificación. En los primeros siglos en que aparece la forma DAR gana, tal especificación se podía alcanzar mediante diversos recursos: el empleo de una frase preposicional con de acompa- 
ñada por un sustantivo (13a) o por una oración de infinitivo (13b), el empleo de una oración de infinitivo o de una oración con verbo finito, sin que mediara una preposición (13c y d) o el uso del pronombre tal (13e):

(13) a. y le da gana de Dios (s. Xvi, San Juan de la Cruz, Noche oscu$r a)$.

$b$. En parte me dio gana de reír (s. XVII, Francisco de Quevedo, La vida del Buscón llamado don Pablos).

c. Rogad a Dios que me dé gana hazerlo (s. Xvi, Alonso de Villegas, Fructus sanctorum y quinta parte del Flossanctorum).

$d$. Todos éstos eran de una edad y semejantes de cuerpos y fuerças, los cuales tenía el rey para dar gana a sus hijos que se exercitassen en las armas (s. XVI, Anónimo, Baldo).

e. Tengo una casilla agradable, donde, aunque estrecha, tiene aposento don Francisco de Corral si volviere a dar otro golpe al clavo que no acaba de hincarse. Ojalá que tal le diese gana... (s. XviI, Luis de Góngora, Epistolario) ${ }^{14}$.

Estos ejemplos muestran que en los siglos XVI y XVII se daba cierta variación; no obstante, en el corpus, la mayoría de estas opciones son más bien casos únicos o casi únicos (no más de dos por siglo). El esquema que se estaba imponiendo era $d e+$ $\mathrm{O}_{\mathrm{INF}}$, como en $(13 b)$.

Otro recurso que tenía el hablante era la complementación nula, normalmente en una anáfora cero, como ocurre en (14):

(14) Que se assome a la ventana $\mathrm{i}_{\mathrm{i}}$ la vez que le diere gana $\emptyset_{\mathrm{i}}$ (s. XVII, Anónimo, Segunda parte del Romancero general y Flor de diversa poesia),

donde le diere gana se interpreta como referido a lo dicho previamente, esto es, le diere gana (de) asomarse a la ventana.

Para los siglos XVIII y XIX los patrones constructivos con DAR gana se reducen a dos: $d e+\mathrm{INF}$, o complementación nula. Ahora bien, en cuanto al resto de estas construcciones con gana, para el siglo xIX cada una de ellas termina por emplearse preferentemente en uno $\mathrm{u}$ otro de estos dos patrones constructivos (cf. Cuadro 4).

14 Se admite que tal también pueda entenderse como referido a un sujeto, pero me parece más natural, por la mayor cercanía referencial, interpretar tal como referido a tener aposento, esto es: "Ojalá que le diese gana tener aposento (aquí)...", y no "Ojalá que la casilla agradable le diese gana”. 


\section{Cuadro 4}

Frecuencia del complemento de $+O_{I N F}$ vs. complementación nula $(\text { s. XIX) })^{15}$

\begin{tabular}{lrrrr}
\hline & \multicolumn{2}{c}{$d e+O_{I N F}$} & \multicolumn{2}{c}{ complementación nula } \\
\hline DAR gana & $49 \%$ & $(21 / 43)$ & $51 \%$ & $(22 / 43)$ \\
DAR la gana & $15 \%$ & $(54 / 356)$ & $84.5 \%$ & $(301 / 356)$ \\
DAR.SG. ganas & $83 \%$ & $(10 / 12)$ & $8 \%$ & $(1 / 12)$ \\
DAR ganas & $96.5 \%$ & $(85 / 88)$ & $1 \%$ & $(1 / 88)$ \\
\hline
\end{tabular}

Considerando únicamente estas dos opciones, se observa que para el siglo XIX, mientras que con DAR.SG. ganas y DAR ganas la opción claramente preferida es $d e+\mathrm{O}_{\mathrm{INF}}(83$ y $96.5 \%$, respectivamente), con DAR la gana se da la tendencia contraria, pues la construcción propende a fijarse con la complementación nula $(84.5 \%)$. Con DAR gana se recurre casi con la misma frecuencia al complemento $d e+\mathrm{O}_{\mathrm{INF}}(49 \%)$ que a la complementación nula ( $51 \%$ ), en consonancia con la ambigüedad de esta construcción, que puede interpretarse como DAR ganas o como DAR la gana, como señalábamos al inicio.

Las construcciones con gana se acoplarían pues a la tendencia a emplear $d e+\mathrm{O}_{\mathrm{INF}}$ en las oraciones completivas de sustantivo, establecida en el español medio (cf. Bogard y Company 1989; Girón Alconchel 2013, pp. 877-879; Moreno de Alba 2009). Discursivamente, sin embargo, se establecería una diferencia entre aquellas construcciones que siguen dicho patrón (DAR.SG. ganas, DAR ganas) y aquellas en las que se prefiere la complementación nula, esto es, aquellas que se emplean preferentemente cuando se considera que el complemento es accesible al oyente y por tanto no hay necesidad de enunciarlo (DAR la gana). Asimismo, se ha señalado que los constructos verbonominales -en los que cabría incluir las distintas locuciones aquí analizadas- presentan una baja expansión (cf. Company 2006, p. 518). En el caso de las construcciones que nos ocupan, se dio una diferenciación entre aquellas sin expansión y aquellas que suelen emplearse con una expansión (vía frase preposicional).

15 Omito aquí los casos en que la frase queda inconclusa $(d e \ldots)$. Con la construcción DAR la gana se recurre en el s. XIX a la inclusión de una oración finita con que en vez del complemento $d e+\mathrm{O}_{\mathrm{INF}}(1$ caso) . 
Diferenciación semántica

Al inicio de este trabajo hemos dicho que DAR ganas apunta a una disposición mental débil (similar al "deseo") e incluye una disposición física, y DAR la gana apunta a una disposición mental fuerte (similar a la "voluntad"). Ahora bien, una aproximación diacrónica a tales matices puede alcanzarse mediante la observación de los verbos y predicados con los que se combinan estas expresiones modales, esto es, el complemento de tipo oracional previsto sintácticamente y al que hemos hecho referencia en el apartado anterior. De los distintos tipos de verbos optamos por seleccionar dos en el análisis: $a$ ) verbos o predicados que indican una acción relativa a una función biológica (como puede ser comer, defecar, vomitar, dormir) o a una reacción física (como puede ser reír, llorar) (cf. $4 a$ repetido aquí como 15), y b) verbos o predicados de afección, comunicación y pensamiento (cf. 16) ${ }^{16}$ :

(15) CAÇA, quita los malos pensamientos e la saña, e da gana de comer al que lo acostumbra, e de dormir (s. XVI, Hugo de Celso, Repertorio universal de todas las leyes de estos reinos de Castilla).

(16) Suplico a vuestras mercedes que se me dé licencia para contar un cuento breve que sucedió en Sevilla, que, por venir aquí como de molde, me da gana de contarle (s. XvII, Miguel de Cervantes, Segunda parte del ingenioso caballero don Quijote de la Mancha).

Estos dos tipos nos permitirán apreciar el comportamiento semántico de las colocaciones que hemos venido analizando, específicamente en relación con eventos asociados al cuerpo y a aquellos de mayor abstracción, o sea, el rasgo de disposición física al que hemos hecho referencia con DAR ganas y el carácter mental de DAR la gana.

Si se observa la frecuencia total de aparición de estos verbos o predicados por colocación (cf. Cuadro 5), tenemos que en dos de ellas, DAR gana y DAR ganas, no se aprecia una diferencia significativa entre ambos tipos, con porcentajes de alrededor del 20\%. Con las dos restantes, en cambio, se establece una

16 Sigo aquí la clasificación de la tradición latina que agrupa este tipo de verbos; sin embargo, hemos excluido los verbos de percepción física. Éstos implicarían tanto una acción corporal como mental. 
diferencia. En el caso de DAR la gana el porcentaje de verbos de afección, comunicación y pensamiento en la oración completiva es bastante más alto: $21 \%$ vs. un $2 \%$ de verbos relativos a una función biológica o reacción física. Con DAR.SG. ganas la relación es inversa y bastante más marcada: $62.5 \%$ con verbos relativos a una función biológica o reacción física y $6 \%$ con verbos de afección, comunicación y pensamiento.

\section{CUADro 5}

Frecuencia de verbos de función biológica vs. verbos de comunicación y pensamiento en la oración completiva (ss. XVI-XIX)

\begin{tabular}{lcccr}
\hline & \multicolumn{2}{c}{$\begin{array}{l}\text { Verbos de acción relativa } \\
\text { a una función biológica } \\
\text { o reacción física }\end{array}$} & \multicolumn{2}{c}{$\begin{array}{c}\text { Verbos de afección, } \\
\text { comunicación } \\
\text { y pensamiento }\end{array}$} \\
\hline DAR gana & $22 \%$ & $(29 / 131)$ & $17.5 \%$ & $(23 / 131)$ \\
DAR la gana & $2 \%$ & $(8 / 405)$ & $21 \%$ & $(85 / 405)$ \\
DAR.SG. ganas & $62.5 \%$ & $(10 / 16)$ & $6 \%$ & $(1 / 16)$ \\
DAR ganas & $19.5 \%$ & $(18 / 92)$ & $23 \%$ & $(21 / 92)$ \\
\hline
\end{tabular}

La información diacrónica arroja otros datos de interés (cf. Cuadros 6 y 7). Decíamos que tomados los datos en su conjunto no se apreciaban diferencias entre uno y otro tipo de verbos con DAR gana, mas no ocurre lo mismo en la dimensión diacrónica: mientras que con los verbos de comunicación y pensamiento se observa cierta oscilación de un siglo a otro (cf. el descenso en el siglo XVIII, apreciable en el Cuadro 7), que cabe atribuir a los temas tratados en los textos, los verbos de función biológica o reacción física muestran un claro descenso en su frecuencia (Cuadro 6). Así, en el siglo xvi se emplean un $46 \%$ de las veces; en el XVII, un $23.5 \%$; en el XVIII, un $16 \%$, y en el XIX, un $11 \%$. Puede lanzarse la hipótesis, entonces, de que el sustantivo gana se empleaba inicialmente en relación con acciones vinculadas a funciones corporales y que con el tiempo se ampliaron sus usos para incluir otro tipo de predicados de carácter más abstracto, como serían los verbos de afección, comunicación y pensamiento. Los datos de las otras colocaciones apoyan tal hipótesis. En el siglo XVII, cuando se documentan las primeras instancias de DAR la gana y DAR.SG. ganas, con ninguna de las dos se registran casos con verbos de comunicación y pensamien- 
to, pero sí con los verbos de función biológica o reacción física (50 y $100 \%$ ). Para el siglo XVIII, empieza a darse una especialización semántica y cada colocación muestra un perfil distinto, al emplearse preferentemente con una u otra de estas clases: $50 \%$ de verbos de función biológica con DAR.SG. ganas y $4.2 \%$ con DAR la gana; $0 \%$ de verbos de comunicación y pensamiento con DAR.SG. ganas y $21 \%$ con DAR la gana. Por su parte, la nueva construcción en ese siglo, DAR ganas, aparece con verbos de comunicación y pensamiento, pero no se documenta con verbos de función biológica (aunque sí en el s. XIX, con un 20.5\%).

\section{CuAdro 6}

Frecuencia de verbos de función biológica en la oración completiva por siglo

\begin{tabular}{|c|c|c|c|c|c|c|}
\hline & & s. XVI & & $X V I I$ & s. XVIII & s. $X I X$ \\
\hline DAR gana & $46 \%$ & $(11 / 24)$ & $23.5 \%$ & $(8 / 34)$ & $16 \% \quad(5 / 30)$ & $11 \% \quad(5 / 43)$ \\
\hline DAR la gana & & & $50 \%$ & $(1 / 2)$ & $4.2 \% \quad(2 / 47)$ & $1.5 \% \quad(8 / 405)$ \\
\hline DAR.SG. ganas & & & $100 \%$ & $(2 / 2)$ & $(1 / 2)$ & $58 \% \quad(7 / 12)$ \\
\hline DAR ganas & & & & & $0 \% \quad(0 / 4)$ & $20.5 \% \quad(18 / 88)$ \\
\hline
\end{tabular}

\section{CUADro 7}

Frecuencia de verbos de afección, comunicación y pensamiento en la oración completiva por siglo

\begin{tabular}{|c|c|c|c|c|c|c|c|}
\hline & s. $X V I$ & \multicolumn{2}{|c|}{ s. XVII } & \multicolumn{2}{|c|}{ s. XVIII } & \multicolumn{2}{|c|}{ s. $X I X$} \\
\hline DAR gana & $16.5 \% \quad(4 / 24)$ & $17.5 \%$ & $(6 / 34)$ & $3.5 \%$ & $(1 / 30)$ & $28 \%$ & $(12 / 43)$ \\
\hline DAR la gana & & $0 \%$ & $(0 / 2)$ & $21 \%$ & $(10 / 47)$ & $21 \%$ & $(75 / 356)$ \\
\hline DAR.SG. ganas & & $0 \%$ & $(0 / 2)$ & $0 \%$ & $(0 / 2)$ & $8.5 \%$ & $(1 / 12)$ \\
\hline DAR ganas & & & & $25 \%$ & $(1 / 4)$ & $23 \%$ & $(20 / 88)$ \\
\hline
\end{tabular}

En suma, el sustantivo gana se habría empleado inicialmente asociándolo con acciones biológicas o de reacción física, para luego utilizarse con verbos de carácter más abstracto. Algunas de las colocaciones favorecieron uno u otro de estos perfiles semánticos. DAR la gana se distinguiría por emplearse menos con verbos o predicados asociados a funciones biológicas y más con procesos mentales, de carácter más abstracto. Esta asocia- 
ción con procesos mentales, creemos, se habría incorporado a la construcción en forma tal que incluso al emplearse con verbos o predicados de función biológica se interpretan no como mera reacción corporal, sino como una disposición mental, es decir, con un componente de "voluntad". Por su parte, DAR.SG. ganas habría favorecido los verbos asociados a funciones biológicas. No obstante, en este último caso, los datos deben tomarse con precaución, pues, como hemos visto en los apartados anteriores, la colocación no parece haberse estabilizado sintácticamente. Por último, para el siglo XIX, DAR ganas se utiliza con ambos tipos de verbos.

\section{Fórmulas indefinidas}

Hemos señalado que el empleo de DAR la gana experimenta un aumento notable en el siglo xix e indicábamos que ello se relacionaba con su uso para expresar la indefinición, a semejanza (cabría añadir) de cualquier(a). La similitud entre ambas construcciones se explica no sólo por su carácter indefinido, sino también considerando las configuraciones sintácticas en que participa DAR la gana y que comparten ciertos rasgos con la configuración diacrónica de cualquier(a). El ahora pronombre indefinido cualquier(a) surge a partir de construcciones subordinadas con el esquema cual + QUerer, esto es, como unidades separadas que progresivamente van adquiriendo mayor cohesión hasta quedar en cualquier(a) (Company y Pozas 2009; Rivero 1988; Haspelmath 1997, pp. 133-135) ${ }^{17}$. El significado de indefinición surge de una desemantización de la fórmula NEXO + EXPRESIÓN VERBAL DE DISPOSICIÓN MENTAL. LOS nEXOS a que nos referimos han sido clasificados en forma variable, como conjunciones, adverbios o pronombres; común a todos ellos es el hecho de introducir oraciones subordinadas, sean construcciones de relativo libres o con antecedente, construcciones completivas o de otro tipo (causales, etc.). El nexo sólo indica una función gramatical de subordinación (significado procedimental) o, en algunos casos, un rasgo semántico general (p.ej., 'persona' con quien, o 'manera', 'tiempo', etc., con los adverbiales como, cuando...). De los nexos simples en español

17 En la tradición latinista se da un tratamiento distinto. Cf. MEnÉndez PidAl 1985, p. 264. 
(no compuestos ni locucionales, o sea, el simple que, quien, como, etc.), repetidas veces se ha señalado su vínculo con los pronombres interrogativos, empleados para solicitar información que precise la identidad del referente. Esto es: por sí mismos no permiten identificar un referente de manera unívoca. Tales factores contribuyen a la baja informatividad de esta construcción esquemática. El otro elemento que interviene es la expresión verbal de disposición mental. Tomemos el ejemplo (17) proveniente del corpus:

(17) Que cada uno multa como le da la gana... (s. xIx, Mariano José de Larra, Por ahora).

Para apreciar el intercambio de información que tiene lugar, pensemos en un posible diálogo:

(18) -Que cada uno multa...

-¿Cómo?

-Como le da la gana.

A la pregunta ¿cómo?, que busca precisar el modo en que se lleva a cabo la acción, la respuesta es como le da la gana, parafraseable de la siguiente forma: 'en el modo de acuerdo con su voluntad del momento'. Es decir, no se precisa una referencia (como sería amablemente, etc.), sino que se indica una condición previa para llevar a cabo la acción de cierta manera y no de otra ${ }^{18}$. El hecho de que la expresión verbal de disposición mental sólo indique una condición previa también contribuye a una baja informatividad que deviene en indefinición. Por tanto, no sólo los factores sintáctico-semánticos, sino también pragmáticos, dan origen a estas fórmulas.

En los estudios semánticos, la definitud se ha examinado considerando la identificabilidad del referente y su pertenencia a un conjunto, del que tanto oyente como receptor tienen noticia o cuya representación les es accesible, y en el que se puede localizar unívocamente el referente (cf. Leonetti 1999; Lyons 1999, pp. 253-274). De la mayor indefinición a mayor definición (i.e. menos identificable a más identificable) se da un continuo, dentro del cual las fórmulas indefinidas que nos ocupan pasa-

18 SEARLE 1994 [1969] ha estudiado el tratamiento de acciones y condiciones previas en relación con los actos de habla; de manera más general, cf. Habermas 1995. 
rían de la completa indefinición a una delimitación débil en términos, para el caso que aquí nos interesa, de "dar la gana", es decir, señalando "el conjunto de entidades que pueden dar la gana', aunque todavía sin permitir identificar alguna de manera unívoca. En un primer momento, en ellas se conserva, pues, la carga semántica de la construcción en términos de 'ocurrir acorde a la voluntad', si bien tales fórmulas parecen haberse desemantizado para señalar una mera marca de indefinitud como veíamos en el ejemplo (3). Discursivamente es posible que se den algunas indicaciones respecto al rango de probabilidades sobre el que podría llevarse a cabo una identificación, que quedaría todavía en el ámbito de lo muy débilmente definido. La indefinición en estas construcciones va asociada al concepto de elección libre, por el que el hablante no da una indicación precisa respecto a la identificabilidad del referente y deja al oyente la tarea de elegir libremente el referente en cuestión (Haspelmath 1997; Company y Pozas 2009). En la tradición hispánica, este rasgo se estudia bajo el concepto de indistinción o indiferencia propuesto por Fernández Ramírez (1986). En lo particular, tipológicamente se ha señalado que las fórmulas indefinidas que nos ocupan, específicamente con las relativas libres, presentan un bajo grado de gramaticalización y son recurso frecuente para expresar la indefinición en lenguas que no disponen de procedimientos más gramaticales para ello (Haspelmath 1997, pp. 55, 143-147). En este trabajo se considera que, si bien tales fórmulas se empleaban prototípicamente en construcciones de relativo, se fueron extendiendo para incluir otro tipo de estructuras de subordinación.

Ahora bien, como veremos, DAR la gana, y no las otras colocaciones con gana, ha sido la seleccionada para aparecer en este tipo de entornos sintácticos. Ello ha contribuido a la fijación de estas fórmulas. En lo que sigue, analizamos tres rasgos en la comparación entre las distintas colocaciones con gana: tipo de oración en la que participan, nexo empleado y verbos de los que depende la subordinada, rasgo con el que se aprecia una fórmula particular con hacer.

\section{Tipo de oración}

En un trabajo anterior (Ruiz Velasco 2017) señalábamos que DAR la gana y DAR ganas contrastan en el tipo de oración en 
el que aparecen. Si comparamos de manera global el hecho de que aparezcan en una oración principal o en una oración enlazada, sea por estar subordinadas, entrar en una correlación o, en general, estar marcadas como dependientes, la diferencia entre ambas construcciones es significativa (cf. Cuadro 8). Mientras que DAR la gana aparece mayormente en oraciones enlazadas $(86 \%)$, con DAR ganas se da la relación contraria y se emplea sobre todo en oración principal $(70 \%)$, tendencia que parece seguir DAR.SG. ganas $(62 \%)^{19}$. En cambio, DAR gana muestra una diferencia menos marcada, pero tiende a aparecer más en oraciones enlazadas $(66 \%)$ que principales $(34 \%)$.

\section{CuAdro 8}

Tipo de oración por construcción (en porcentaje) (ss. XVI-XIX)

\begin{tabular}{lcccr}
\hline & \multicolumn{2}{c}{ Oración principal } & \multicolumn{2}{c}{ Oración enlazada } \\
\hline DAR gana & $34 \%$ & $(44 / 131)$ & $66 \%$ & $(87 / 131)$ \\
DAR la gana & $14 \%$ & $(56 / 405)$ & $86 \%$ & $(349 / 405)$ \\
DAR.SG. ganas & $62 \%$ & $(10 / 16)$ & $38 \%$ & $(6 / 16)$ \\
DAR ganas & $70 \%$ & $(64 / 92)$ & $30 \%$ & $(28 / 92)$ \\
\hline
\end{tabular}

De hecho, las dos primeras documentaciones que arroja el CORDE de DAR la gana corresponden a oraciones enlazadas (19):

(19) a. Sale por Madrid y come en su coche donde le halla y le da la gana, ya de figón, ya de pastelería, fruta en la plaza y vino en la taberna (s. XviI, Jerónimo de Barrionuevo, Avisos).

$b$. La luna, cuando le da la gana, deja a estos animales a escuras, muriendo de hambre y llenos de angustia (s. XVII, Juan de Zabaleta, El día de fiesta por la tarde).

En ambos casos, se trata de oraciones adverbiales, con donde (19a) y cuando (19b), que cabe considerar como relativas libres. Pasemos a ver pues los nexos empleados en estas oraciones y la generalización con otros conectores además de los adverbiales.

19 Se toma como oración principal aquellas yuxtapuestas, en que se emplea una de las conjunciones $y$, o, pero, mas, o se trata de la apódosis de una condicional. 
Nexo

Si consideramos ahora el nexo, tenemos que globalmente los más empleados con estas colocaciones son porque, que, quien, cuando, como, donde y cuanto (Cuadro 9). Vemos, entonces, que la construcción DAR ganas se distingue por apoyarse en los nexos que $(22 \%)$ y porque $(1 \%)$, mientras que no encontramos ningún caso con los otros enlaces. Una situación semejante se observa con DAR.SG. ganas: el nexo con el que más aparece en oraciones enlazadas es que (19\%), y sólo encontramos otro caso con cuando (6.2\%), mientras que con el resto de los enlaces arriba mencionados no aparece esta colocación. En cambio, DAR gana y DAR la gana sí participan en configuración sintáctica con todos los enlaces: porque, que, quien, cuando, como, donde, cuanto.

De manera global, estos enlaces representan el 52\% de los usos con DAR gana y el $77 \%$ con DAR la gana, mientras que en las colocaciones con el plural ganas ascienden al 23 y $25 \%$. En el caso de DAR gana este comportamiento se explica, como hemos venido señalando, por la ambigüedad de la construcción, que participa en configuraciones sintácticas similares tanto a las de DAR ganas como a DAR la gana. En lo tocante a esta última, en dichas configuraciones, por un lado se afianza el recurso a la anáfora cero en vez del complemento $d e+\mathrm{O}_{\mathrm{INF}} \mathrm{y}$, por otro, participa de las construcciones en que se dan otras expresiones de disposición mental, como gustar, querer, preferir, considerar, etc. ${ }^{20}$ Esto es, las fórmulas de indefinición a que nos hemos referido, en una configuración prototípica de los pronombres indefinidos ${ }^{21}$. El español habría desarrollado una serie de fórmulas de indefinición, débilmente gramaticalizadas, bajo el esquema NEXO + EXPRESIÓN VERBAL DE DISPOSICIÓN MENTAL, en el que esta última permite indicar diversos matices según la expresión verbal empleada y el nexo hace referencia a categorías ontoló-

${ }^{20}$ El hecho de que en la serie aparezca un verbo como considerar nos lleva a hablar de "verbos de disposición mental". Cf., p.ej., "y todos los empleos estarán en tus manos para repartirlos à quien gustares" (s. XVIII, apud Melis et al. 2003, p. 13), con las posibles variantes: a quien prefieras, a quien quieras, a quien consideres, a quien te dé la gana, etcétera.

${ }^{21}$ Según Haspelmath (1997, pp. 21-29), los pronombres indefinidos son formas derivadas consistentes en un marcador de indefinición más una base con la que se señala cada una de las categorías ontológicas mayores (persona, cosa, tiempo, lugar, etcétera). 
gicas mayores. De las construcciones con gana, DAR la gana es seleccionada para esta función.

Así, desde un punto de vista diacrónico (cf. Cuadro 10), con DAR la gana se observa un afianzamiento de la construcción en configuraciones sintácticas con el que polivalente, quien y los adverbiales básicos (como, cuando, donde, cuanto ${ }^{22}$. Estas distintas opciones se ejemplifican en (20); en ellas se dan las fórmulas de indefinición con complementación nula:

(20) a. Allí puede uno tener la opinión que le dé la gana... (s. XIX, Mariano José de Larra, La policía).

b. Compra, cohecha a quien te dé la gana... (s. XIx, José Milla y Vidaurre, El visitador).

c. Contesto como me da la gana (s. XIx, Jacinto Octavio Picón, La honrada).

d. Voy donde me da la gana (s. XIx, Jacinto Octavio Picón, La honrada).

e. Cásate cuando te dé la gana... (s. XIx, José María de Pereda, Peñas arriba).

f. Pregunte usted lo que quiera y pálpeme cuanto le dé la gana (s. XIX, Sebastián de Miñano, Sátiras y panfletos del trienio constitucional, 1820-1823).

\section{Cuadro 10}

Nexos empleados en configuraciones con DAR la gana por siglo (en porcentaje)

\begin{tabular}{|c|c|c|c|c|}
\hline \multirow[b]{2}{*}{ que } & s. XVII & s. XVIII & \multicolumn{2}{|c|}{ s. XIX } \\
\hline & & $32 \% \quad(15)$ & $35 \%$ & $(125)$ \\
\hline quien & & $6.3 \%$ & $4.4 \%$ & (16) \\
\hline adverbiales básicos & $100 \% \quad(2)$ & $29.7 \% \quad(14)$ & $26.5 \%$ & (94) \\
\hline porque & & $2.1 \%$ & $8.4 \%$ & $(30)$ \\
\hline otros & & $8.5 \%$ & $3.9 \%$ & (14) \\
\hline
\end{tabular}

En cuanto a los cambios registrados, en el paso del siglo XVIII al XIX aumenta considerablemente su empleo con porque, al subir del $2.1 \%$ al $8.4 \%$. En los conectores no básicos

${ }^{22}$ Consideramos estos adverbiales como "básicos” por su carácter simple tanto morfológica como semánticamente (cf. nota anterior). 
(la categoría "otros", en el cuadro), más que un aumento en la frecuencia se observa un aumento en la diversidad de nexos empleados. Así, mientras que en los dos primeros casos de DAR la gana documentados en el CORDE (s. XVII) la construcción ya se empleaba con los adverbiales básicos (cf. ejemplos en 19), en el siglo XIX aparece en configuración sintáctica con hasta que, siempre que, luego que, conforme, según, mientras. Con ello la construcción se generaliza para ser empleada con otros conectores, además de los básicos.

Patrones específicos con verbos: la construcción HACER lo que \{DAR la gana/...\}

Entre las diversas funciones de que con estas construcciones, el nexo puede aparecer en subordinadas adjetivas como en ( $20 a$; repetido aquí como $21 a$ ) o en completivas verbales $(21 b-d)$ :

(21) a. Allí puede uno tener la opinión que le dé la gana (s. XIx, Mariano José de Larra, La policía).

b. Digo que no me da la gana (s. XIx, Benito Pérez Galdós, Napoleón en Chamartín).

c. ¡Dime lo que te dé la gana y te creo! (s. XIX, Joaquín Dicenta, Juan José. Drama en tres actos y en prosa).

d. nosotros haremos lo que nos dé la gana ... (s. xIx, Benito Pérez Galdós, La Corte de Carlos IV).

Cuando se presenta en completivas verbales el nexo tiende a aparecer junto con el artículo neutro $l o(21 c \mathrm{y} d)$, con el que todo el sintagma (lo que te dé la gana, lo que nos dé la gana) es marcado como frase nominal y cuyo significado en primer plano es la unicidad y no la identificabilidad de la entidad, pues la expresión verbal (DAR la gana) no ofrece la información requerida para ello. En las completivas verbales, se observan dos patrones de uso en el corpus: uno con los verbos de comunicación, percepción y entendimiento, que se organizan en torno a decir, con el que puede aparecer en discurso indirecto $(21 b)$ o más comúnmente con el neutro lo (21c), y otro con un verbo todavía con menor carga semántica: hacer $(21 d)$. Con ellos la predicación se hace indefinida según dos esquemas constructivos: 
1) verba dicendi, sentiendi et sciendi, con decir como elemento central que atrae a los otros miembros de la clase, esto es:

DECIR + lo que + EXPRESIÓN VERBAL DE DISPOSICIÓN MENTAL PEDIR

PENSAR

2) HACER, esto es:

HACER + lo que + EXPRESIÓN VERBAL DE DISPOSICIÓN MENTAL

Ahora bien, si consideramos las distintas construcciones con gana, nuevamente se da un comportamiento diferenciado (cf. Cuadro 11). La construcción más empleada en completivas verbales es DAR la gana, uso que corresponde al $25 \%$ de los casos en el corpus; le siguen DAR gana $(11 \%)$ y DAR ganas $(7.6 \%)$; finalmente, con DAR.SG. ganas no se presenta ningún caso. Un buen porcentaje de estas completivas se limita al verbo hacer con la construcción DAR la gana (57\%) y DAR gana (43\%), mientras que las otras construcciones no parecen emplearse en este contexto.

\section{CuAdro 11}

Frecuencia de las completivas de verbo por construcción (ss. XVI-XIX)

\begin{tabular}{lrrrr}
\hline & \multicolumn{2}{c}{$\begin{array}{c}\text { Completivas } \\
(\% \text { del total) }\end{array}$} & \multicolumn{2}{c}{ Hacer } \\
& \multicolumn{1}{c}{$\%$ de las completivas) } \\
\hline DAR gana & $11 \%$ & $(14 / 131)$ & $43 \%$ & $(6 / 14)$ \\
DAR la gana & $25 \%$ & $(100 / 405)$ & $57 \%$ & $(57 / 100)$ \\
DAR.SG. ganas & $0 \%$ & $(0 / 16)$ & $0 \%$ & $(0 / 0)$ \\
DAR ganas & $7.6 \%$ & $(7 / 92)$ & $0 \%$ & $(0 / 7)$ \\
\hline
\end{tabular}

Específicamente, con el complemento con lo inicial se observa que de las colocaciones con gana la que más ha tendido a afianzarse diacrónicamente es DAR la gana (cf. Cuadro 12). Con HACER lo que..., las instancias de DAR la gana pasan del $4.2 \%$ en el siglo XVIII a representar el $15 \%$ en el siglo XIX; en la construcción DEGIR/... lo que..., pasan del $2.1 \%$ en el s. XVIII al $6.7 \%$ en el s. XIX. Con DAR gana el aumento en HACER lo que... es más reducido (6.6\% a 9.3\%), y en DECIR lo que... se mantiene más o menos estable $(3.3 \%$ a $2.3 \%)$. Los hablantes han preferido, pues, DECIR lo que $\{$ DAR la gana/... $\}$ y HACER lo que $\{$ DAR 
la gana/...\} con DAR la gana como elemento en el paradigma de la construcción más que con DAR gana, de manera que la primera se especializa en aparecer en tales contextos.

Cuadro 12

Construcciones con gana en los esquemas con HACER lo que y DECIR lo que por siglo (en porcentaje)

\begin{tabular}{lcccccccccc}
\hline & \multicolumn{2}{c}{$s$. XVI } & \multicolumn{2}{c}{ s. XVII } & \multicolumn{2}{c}{ s. XVIII } & \multicolumn{2}{c}{ s. XIX } & TOTAL \\
\hline HACER lo que P $^{23}$ & & & & & & & & & & \\
DAR gana & $0 \%$ & $(0 / 24)$ & $0 \%$ & $(0 / 34)$ & $6.6 \%$ & $(2 / 30)$ & $9.3 \%$ & $(4 / 43)$ & $4.5 \%$ & $(6 / 131)$ \\
DAR la gana & & & $0 \%$ & $(0 / 2)$ & $4.2 \%$ & $(2 / 47)$ & $15 \%$ & $(53 / 356)$ & $14 \%$ & $(55 / 405)$ \\
DECIR/... lo que & & & & & & & & & & \\
DAR gana & $0 \%$ & $(0 / 24)$ & $0 \%$ & $(0 / 34)$ & $3.3 \%$ & $(1 / 30)$ & $2.3 \%$ & $(1 / 43)$ & $1.5 \%$ & $(2 / 131)$ \\
DAR la gana & & & $0 \%$ & $(0 / 2)$ & $2.1 \%$ & $(1 / 47)$ & $6.7 \%$ & $(24 / 356)$ & $6.1 \%$ & $(25 / 405)$ \\
\hline
\end{tabular}

\section{Conclusiones}

En estas páginas nos hemos ocupado del desarrollo de las construcciones vinculadas a DAR gana y, en particular, del paso de una colocación libre de las palabras en el discurso al establecimiento de determinados patrones sintáctico-semánticos por los que se conforman las distintas construcciones surgidas de DAR gana, es decir, su construccionalización. Así, del esquema de transferencia concreta con el verbo dar, con estas construcciones se pasó a señalar una transferencia abstracta, con un sujeto con el rol semántico de causa y un objeto indirecto recipienteexperimentante, y de ahí a un esquema en que se omite la causa. Con ello, del esquema de transferencia se conserva tan sólo un significado aspectual incoativo. Asimismo, de los posibles complementos del sustantivo hubo una especialización por la que estas construcciones tendieron a emplearse más bien con oraciones completivas $(d e+\mathrm{O}$, y no $d e+\mathrm{N})$. Estas dos características sientan las bases para el uso locucional modal que caracteriza a este tipo de construcciones.

${ }^{23}$ El esquema presenta variantes en las que se emplea aquello que o cuanto en vez de lo que. Éstas no se incluyen en el cuadro; de cada una se encontró un caso. 
En lo particular a cada una de ellas, la variante DAR.SG. ganas tuvo menor difusión y presenta rasgos variables, sin llegar a fijarse en un patrón constructivo. Entre las opciones con el sustantivo en plural, la construcción que se impone es DAR ganas, cuya estructura es más transparente (con el sustantivo ganas como tema y sujeto) y con una referencia que ha de especificarse mediante un complemento, fijado en la forma $d e+\mathrm{O}$. Por su parte, la construcción DAR la gana se fija fuertemente con dos rasgos: la presencia de un pronombre clítico que señala al recipiente-experimentante y el complemento nulo. Finalmente, DAR gana, la construcción más añeja, presenta rasgos comunes a estas dos.

En este reacomodo de funciones debe de haberse dado una serie de influencias mutuas entre distintas construcciones, como aquellas entre los verbos placer, pesary gustar, en las que se fija un objeto indirecto con el rol de experimentante (cf. Melis et al. 2003, pp. 2-26), y las construcciones de dar con un sustantivo de afección, de las que DAR gana es en su origen una instancia particular.

En lo tocante a la semántica de estas construcciones los datos apuntan a que DAR gana se empleaba inicialmente con acciones biológicas o de reacción física para extenderse a acciones más abstractas. En los períodos considerados, DAR la gana, en consonancia con la caracterización que hemos hecho al inicio de este artículo en términos de que indica una disposición mental, se emplea menos con predicados asociados a funciones biológicas y más con predicados de afección, comunicación y pensamiento. DAR.SG. ganas se emplea, por el contrario, más con verbos asociados a funciones biológicas. Finalmente, DAR ganas pasa a emplearse con ambos tipos de predicados en el siglo XIX. Una revisión que considere el siglo xx permitiría precisar el devenir diacrónico de esta construcción y qué tanto absorbió la función que cumplía DAR.SG. ganas con los verbos de función biológica.

Finalmente, hemos visto una especialización de DAR la gana para aparecer en oraciones subordinadas. En la época en que surge dicha construcción está teniendo lugar una reestructuración del modo en que se organiza el discurso en lengua española. De las conjunciones heredadas del latín, el español desarrolla una serie de locuciones conjuntivas como parte de la elaboración interna de la lengua, de manera que en el s. XviII disminuye el recurso a la adición y la parataxis para intensifi- 
carse el empleo de la hipotaxis en la cohesión textual (Girón 2013, pp. 882-884). De las construcciones con gana, la que es seleccionada por los hablantes para utilizarse en tales contextos es DAR la gana, y es en los siglos XVIII y XIX que su uso se fija y aumenta considerablemente. Ello se convierte en el afianzamiento de las fórmulas de indefinición a que hemos hecho referencia, su generalización para emplearse con nexos subordinadores diversos (lo que permite mayores matizaciones en el discurso) y su especialización en las construcciones verbales HACER lo que... y DECIR/... lo que.... Se trata de una particularidad de esta construcción, pues las construcciones con ganas plural (DAR ganas, DAR.SG. ganas), como hemos visto, no presentan tales patrones de uso. En cambio, la construcción más antigua, DAR gana, comparte algunos de estos usos con DAR la gana, pero muestra un perfil menos diferenciado, por lo que se mantiene ambigua. Como se ha observado en otros casos (cf. Bybee 2010, pp. 67-69), la esquematicidad de las fórmulas de indefinición en que participa DAR la gana y en las que alterna con otras expresiones verbales de disposición mental contribuye a que aumente marcadamente su productividad en el siglo XIX.

\section{REFERENCIAS}

Alcina Franch, Juan y José Manuel Blecua 1975. Gramática española, Ariel, Barcelona.

Bosque, Ignacio y Violeta Demonte (dirs.) 1999. Gramática descriptiva de la lengua española, Espasa Calpe, Madrid, 3 ts.

Blank, Andreas 2001. Einführung in die lexikalische Semantik, Niemeyer, Tübingen.

Bogard, Sergio y Concepción Company 1989. "Estructura y evolución de las oraciones completivas de sustantivo en el español”, Romance Philology, 43, 2, pp. 258-273.

Bybee, JoAn 2010. Language, usage and cognition, Cambridge University Press, Cambridge.

Bybee, Joan, Revere Perkins \& William Pagliuca 1994. The evolution of grammar. Tense, aspect, and modality in the languages of the world, University of Chicago Press, Chicago-London.

Cano Aguilar, Rafael 1981. Estructuras sintácticas transitivas en el español actual, Gredos, Madrid.

Company Company, Concepción 2006. "El objeto indirecto", en Sintaxis histórica de la lengua española. Primera parte: La frase verbal. Dir. C. Company Company, Universidad Nacional Autónoma de México-Fondo de Cultura Económica, México, t. 1, pp. 477-572. 
Company Company, Concepción y Julia Pozas loyo 2009. "Los indefinidos compuestos y los pronombres genérico-impersonales omne y uno", en Sintaxis histórica de la lengua española. Segunda parte: La frase nominal. Dir. C. Company Company, Universidad Nacional Autónoma de México-Fondo de Cultura Económica, México, t. 2, pp. 1073-1219.

CORDE = Real Academia Española: Banco de datos (CORDE) [en línea]. Corpus diacrónico del español, http:/ / www.rae.es [consultado el 16 de abril de 2017].

Corominas, Joan 1955. Diccionario crítico etimológico de la lengua castellana, Francke, Bern.

Corpas Pastor, Gloria 1996. Manual de fraseología española, Gredos, Madrid.

Coseriu, Eugenio 1988. "Vom Primat der Geschichte", en Energeia und Ergon. Sprachliche Variation - Sprachgeschichte - Sprachtypologie. Hrsg. Jörn Albrecht, Gunter Narr, Tübingen, t. 1, pp. 131-146.

CREA = Real Academia Española: Banco de datos (CREA) [en línea]. Corpus de referencia del español actual, http://www.rae.es [consultado el 23 de agosto de 2008].

Cuervo, Rufino José 1998. Diccionario de construcción y régimen de la lengua castellana, Instituto Caro y Cuervo-Herder, Barcelona.

Delbecoue, Nicole y Béatrice Lamiroy 1999. "La subordinación sustantiva: las subordinadas enunciativas en los complementos verbales", en Gramática descriptiva de la lengua española. Dirs. I. Bosque y V. Demonte, Espasa Calpe, Madrid, pp. 1965-2082.

Eberenz, Rolf 2009. "La periodización de la historia morfosintáctica del español: propuestas y aportaciones recientes”, Cahiers d'Études Hispaniques Médiévales, 32, pp. 181-201, doi: https://doi.org/10.3406/ cehm.2009.2072.

Fernández Ramírez, Salvador 1986 [1951]. Gramática española. T. 4: El verbo y la oración. Ed. Ignacio Bosque, Arco-Libros, Madrid.

Fernández Soriano, Olga y Susana Táboas Baylín 1999. "Construcciones impersonales no reflejas", en Gramática descriptiva de la lengua española. Dirs. I. Bosque y V. Demonte, Espasa Calpe, Madrid, pp. 1723-1778.

Fillmore, Charles J., Paul Kay \& Mary Catherine O'Connor 1988. "Regularity and idiomaticity in grammatical constructions: The case of let alone", Language, 64, 3, pp. 501-538, doi: 10.2307/414531.

Fried, Mirjam 2013. "Principles of constructional change", en The Oxford handbook of construction grammar. Eds. Thomas Hoffmann \& Graeme Trousdale, Oxford University Press, Oxford, pp. 419-438.

Girón Alconchel, José Luis 2013 [2004]. "Cambios gramaticales en los Siglos de Oro", en Historia de la lengua española. Coord. Rafael Cano, Ariel, Barcelona, pp. 859-893.

GiRY-SCHNEIDER, JaCQUELINE 1986. "Les noms construits avec faire: compléments ou prédicats?”, Langue Française, 69 (Syntaxe des noms), pp. 49-63, doi: 10.3406/lfr.1986.6362.

Givón, T. 2001. Syntax. An introduction, John Benjamins, Amsterdam-Philadelphia, t. 1.

Goldberg, Adele 1995. Constructions. A construction grammar approach to argument structure, University of Chicago Press, Chicago-London. 
Gross, Gaston et Robert Vivès 1986. "Les constructions nominales et l'élaboration d'un lexique-grammaire", Langue Française, 69 (Syntaxe des noms), pp. 5-27, doi: 10.3406/lfr.1986.6360.

Habermas, Jürgen 1995. Theorie des kommunikativen Handelns. Band 1: Handlungsrationalität und gesellschaftliche Rationalisierung, Suhrkamp, Frankfurt/M.

Haspelmath, Martin 1997. Indefinite pronouns, Oxford University Press, Oxford.

Hernanz, M. Lluïsa 1999. "El infinitivo", en Gramática descriptiva de la lengua española. Dirs. I. Bosque y V. Demonte, Espasa Calpe, Madrid, pp. 2197-2356.

Hopper, Paul J. \& Elizabeth Closs Traugott 2003. Grammaticalization, Cambridge University Press, Cambridge.

LAKoff, GEORge y MARK Johnson 1986. Metáforas de la vida cotidiana, Cátedra, Madrid.

LAPeSA, Rafael 1981, Historia de la lengua española, Gredos, Madrid.

LEHMANN, Christian 1985. "Grammaticalization: Synchronic variation and diachronic change”, Lingua e Stile, 20, pp. 303-318.

Lehmann, Christian 1989. "Grammatikalisierung und Lexikalisierung", Zeitschrift für Phonetik, Sprachwissenschaft und Kommunikationsforschung, 42, pp. 11-19.

Lehmann, Christian 2002. Thoughts on grammaticalization, Universität Erfurt, Erfurt (Arbeitspapiere des Seminars für Sprachwissenschaft der Universität Erfurt, 9).

Lehmann, Christian 2002a. "New reflections on grammaticalization and lexicalization", en New reflections on grammaticalization. Eds. Ilse Wischer \& Grabriele Diewald, John Benjamins, Amsterdam-Philadelphia, pp. 1-18, http://www.uni-erfurt.de/sprachwissenschaft/personal/lehmann/CL_ Publ/New_reflections.pdf [consultado el 8 de mayo de 2017].

LeOnetti, Manuel 1999. "El artículo", en Gramática descriptiva de la lengua española. Dirs. I. Bosque y V. Demonte, Espasa Calpe, Madrid, pp. 787890.

LINELL, PER 2005. The written language bias in linguistics. Its nature, origins and transformations, Routledge, London-New York.

Lyons, Christopher 1999. Definiteness, Cambridge University Press, Cambridge.

Melis, Chantal, Marcela Flores y Sergio Bogard, 2003. "La historia del español. Propuesta de un tercer período evolutivo", Nueva Revista de Filología Hispánica, 51, pp. 1-56, doi: http:/ /dx.doi.org/10.24201/ nrfh.v51il.2202.

Menéndez Pidal, R. 1985. Manual de gramática histórica española. Espasa-Calpe, Madrid.

Moreno de Alba, José G. 2009. "Sintagmas completivos del nombre: complementos adnominales y oraciones subordinadas completivas del nombre”, en Sintaxis histórica de la lengua española. Segunda parte: La frase nominal. Dir. C. Company Company, Universidad Nacional Autónoma de México-Fondo de Cultura Económica, México, t. 2, pp. 1321-1409.

Penny, Ralph 2014. Gramática histórica del español, Ariel, Barcelona. 
Rivero, María-Luisa 1988. "La sintaxis de qual quiere y sus variantes en el español antiguo”, Nueva Revista de Filología Hispánica, 36, pp. 47-73, doi: http:/ /dx.doi.org/10.24201/nrfh.v36i1.663.

Ruiz Velasco, Liliana 2017. "Porque me da la gana o la razón de la sinrazón. Un análisis construccional”, Lingüistica Mexicana, 9, 1, pp. 19-42.

SEArle, John 1994 [1969]. Actos de habla, Cátedra, Madrid.

Seco, Rafael 1978. Manual de gramática española, Aguilar, Madrid.

Seco, Manuel et al. 1999. Diccionario del español actual, Aguilar, Madrid. 
